\title{
LA COSMOVISIÓN BÍBLICA VS. LAS TRES MÁS GRANDES COSMOVISIONES DE LA HUMANIDAD
}

\author{
Jesús Hanco Torres \\ jesushan@upeu.edu.pe \\ Universidad Peruana Unión
}

Resumen

\begin{abstract}
A través de los tiempos, han existido cosmovisiones que han marcado hitos en la historia de la humanidad. El presente artículo tiene por objetivo abordar tres cosmovisiones que más han impactado la historia de la humanidad, a saber, el idealismo, el realismo y el posmodernismo, presentando el trasfondo histórico de cada una de las cosmovisiones, sus principales propuestas filosóficas y luego realizar un contraste a la luz de la cosmovisión bíblica. La cosmovisión bíblica está descrita en la Palabra de Dios y en la medida que el hombre conozca a Dios, por medio del estudio de la Biblia, tendrá mejores herramientas para evaluar la cosmovisión de su contexto y vivir según la cosmovisión bíblica.
\end{abstract}

Palabras clave: Cosmovisión, idealista, realista, posmoderno, cristiano. 


\title{
THE BIBLICAL WORLDVIEW VS. THE THREE LARGEST WORLD VIEWS OF MANKIND
}

\begin{abstract}
Through the ages, there have been worldviews that have marked milestones in the history of mankind. This article aims to address three worldviews that have impacted the history of mankind, namely, idealism, realism and postmodernism, presenting the historical background of each of the worldviews, their main philosophical proposals and then perform contrast in the light of the biblical worldview. The biblical worldview is described in the Word of God and to the extent that man knows God through Bible study will have better tools to assess the worldview of its context and to live according to biblical worldview.
\end{abstract}

Keywords: Worldview, idealistic, realistic, postmodern, Christian. 


\section{Introducción}

A través de los tiempos, dentro de la sociedad, se han ido gestando diversas preguntas como: ¿Cuál es el origen del hombre? ¿Cuál es el propósito de la existencia de la raza humana? ¿Cuál es la realidad de todas las cosas? ¿Cómo encontrar el conocimiento y la verdad? ¿Cuál es la verdadera fuente del conocimiento? ¿De qué manera podemos resolver el problema de los valores éticos dentro del hombre? ¿Cómo se determina lo que es malo y lo que es bueno?

126 Y a medida que estas preguntas se han ido respondiendo, desde diversas perspectivas a través de la historia, dichas respuestas se han tornado en la base sobre la cual las personas toman decisiones, vierten opiniones y desarrollan su estilo de vida. Y es este grupo de respuestas las que forman parte de la así llamada: "cosmovisión".

Al abordar el término cosmovisión, se puede observar que etimológicamente deriva de las palabras griegas: kosmos (mundo, universo) y visión (punto de vista particular sobre un tema, un asunto). Otra definición es la proveída por la Real Academia de la Lengua Española que la define como: "manera de ver e interpretar el mundo".

Por lo cual, se podría definir a la cosmovisión como: el conjunto de ideologías (sean estas verdaderas o falsas, conscientes o inconscientes, consistentes o inconsistentes) que guían las decisiones de un individuo al interpretar el mundo que lo rodea. De manera que todo lo que una persona hace (pensar, vestir, comer, creer, etc.) lo hace basado en la cosmovisión que tiene.

Asimismo, a través de los tiempos, han existido cosmovisiones que han marcado hitos en la historia de la humanidad. El presente artículo tiene por objetivo abordar tres cosmovisiones que más han impactado en la historia de la humanidad: el idealismo, el realismo y el posmodernismo, presentando el trasfondo histórico de

${ }^{1}$ Diccionario de la lengua española: vigésima segunda edición, s.v. "cosmovisión”, http://lema.rae.es/drae/?val=cosmovisi\%C3\%B3n (consultado: 22 de noviembre, 2012). 
cada una de las cosmovisiones, sus principales propuestas filosóficas ${ }^{2}$ y luego realizar un contraste, a la luz de la cosmovisión bíblica.

\section{El idealismo platónico}

El idealismo es una cosmovisión que ha ejercido una gran influencia dentro de la humanidad a través de los siglos, y aunque en la cultura occidental actual no se hace mucha mención a esta posición filosófica, todavía indirectamente, cuenta con una gran influencia.

Dicho pensamiento tiene su inicio en el célebre filósofo griego Platón (427-347 a. C.), considerado como el fundador del idealismo, bajo la forma del mito de las cavernas. ${ }^{3}$ En dicho mito se narra

${ }^{2}$ Para poder analizar las propuestas filosóficas, de cada de las cosmovisiones, se subdividirá en tres áreas: la metafísica (¿Cómo se puede describir la realidad última?), la epistemología (¿Cómo se puede alcanzar el verdadero conocimiento?) y la axiología (¿Qué es el valor? ¿Cómo se puede determinar lo que es bueno y lo que es malo?)

${ }^{3}$ Este mito, denominado por algunos como alegoría, aparece al principio del libro VII de la obra la "República" de Platón. la situación de unos prisioneros encadenados (de manos y pies) desde su niñez, quienes tan solo podían observar la pared final de la caverna. Detrás de ellos se hallaba una antorcha encendida, y un sendero donde caminaban otros hombres transportando figuras e imágenes, las cuales generaban sombras. Eran pues dichas sombras las que los prisioneros observan durante toda su vida, creyendo que ellas conformaban la realidad, atribuyendo a estas sombras los sonidos y palabras proferidas por los hombres que transportaban las figuras. El mito continúa con una pregunta: iQué sucedería si se liberase a uno de esos prisioneros y se le obligase a mirar las imágenes que llevan los otros hombres hallados detrás de él, luego la antorcha y, finalmente, el exterior de la caverna?

Platón argumenta que primero el prisionero debería ser llevado a la fuerza pues, en un primer momento, se rehusaría a salir de la caverna y dejar sus cadenas. Pero, poco a poco, conforme iría ascendiendo se daría cuenta del engaño en el cual había estado viviendo 
toda su vida. Convencido que la realidad que había vivido en la caverna era tan solo una sombra del mundo real. Luego de tan brillante descubrimiento, el esclavo iría al interior de la caverna con el fin de liberar a sus demás compañeros de su mundo irreal. Sin embargo, sus antiguos compañeros lo interpretarían como un engaño y de ser posible le matarían, pues preferirían seguir viviendo en su mundo irreal, dentro de la caverna. Es así que Platón presenta una visión de la realidad dividida en dos partes, o llamado así dos mundos:

\section{8}

a. El mundo de las sombras: Este mundo está conformado por las entidades materiales o físicas, que pueden ser percibidas por los sentidos (ojos, oídos, manos). Estos objetos percibidos son materia transitoria e imperfecta, que llegaron a la existencia a causa de las ideas eternas que alguna persona, en algún momento de la historia, las logró percibir. b. El mundo de las ideas: Este mundo está conformado por las ideas, entidades espirituales o mentales. Dichas entidades son la base de la realidad, y son ideales porque representan la perfección de las cosas. Además, la comprensión de este mundo solo es alcanzable para los filósofos, a través del alma racional. Por ejemplo: una mesa que puede ser percibida por los sentidos es solo una sombra de la "mesa ideal", la cual se halla en el mundo de las ideas, y está basada en dicha mesa ideal, que se inventó la mesa que todos percibimos a través de los sentidos.

Esta cosmovisión logró impactar grandemente en el pensamiento cristiano, a través de Agustín de Hipona (s. IV d. C.) quien aceptó la teoría de Platón, redefiniendo la realidad del mundo en dos partes: (1) el mundo eterno y perfecto, donde ubicó a la morada de Dios junto a todos los seres ce- 
lestiales y (2) el mundo imperfecto y finito es el mundo en el cual nos hallamos, donde se aprecia la muerte, el dolor, y donde existe el cambio y el movimiento.

A esto, Agustín añadió la presencia del alma como la parte eterna e imperecedera de cada persona (debido a que pertenece al mundo de Dios), a través del cual se puede tener contacto con el mundo eterno y perfecto de Dios, con el mundo de las ideas.

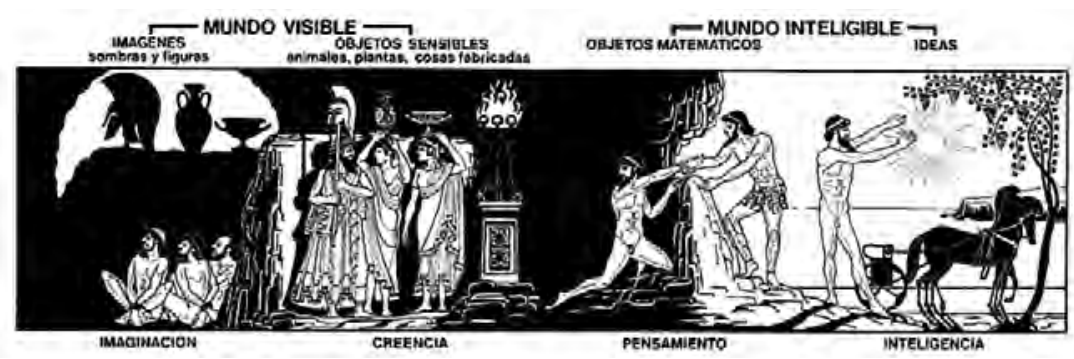

Así, Platón presenta a la verdad como algo eterno, que no puede ser conocida a través del mundo material. Por lo tanto, se hace necesario considerar al mundo de las ideas como la base sobre la cual se ha construido el mundo sensorial. Pues, según Platón, la realidad no puede ser conocida por sí misma, sino debe inferirse de las ideas y representaciones que el sujeto tiene de ellas.

Frente a todo lo mencionado, el idealismo propone que solo aquello que busque imitar el mundo de las ideas es de valor. La hu- manidad llegará a ser moral cuando se halle en acuerdo con la ley moral universal, la cual viene a ser una expresión del carácter del ser absoluto (hallado en el mundo de las ideas). Asimismo, se considera como bello toda aproximación o reflexión de lo ideal. En conclusión, el criterio para diferenciar lo bueno y lo malo no se halla en el ser humano sino fuera de él, en el mundo de las ideas, al cual se puede acceder a través de la reflexión. 
El idealismo platónico frente a la cosmovisión bíblica

El impacto que ha tenido el idealismo dentro del cristianismo ha sido grande, pues el paradigma de dos mundos ha sido de base para la teología católica que, a su vez, ha influido en todos las denominaciones cristianas. Y fue esta visión dualista, de la naturaleza humana, la que ha permitido que muchos cristianos lleguen a las siguientes conclusiones:

a. Todo ser humano está compuesto de un cuerpo mortal y de un alma inmortal.

b. El hombre está compuesto de dos partes: carne (parte mala) y el espíritu (parte buena).

c. El tiempo del ser humano está compuesto de: momento espiritual (por ejemplo: Ir al templo, leer la Biblia, orar, cantar alabanzas a Dios) y momento secular (por ejemplo: ver $\mathrm{TV}$, internet, salir con los amigos, pasear, practicar deporte) donde la invocación a Dios y las creencias cristianas son innecesarias $\mathrm{y}$, en algunos casos, hasta fuera de lugar. ${ }^{4}$

d. La santidad siempre significa solo un momento de separación espacial. Yo no debería tener nada que ver con el mundo. Extracción del mundo es la "esencia" de la santidad.

Sin embargo, al realizar un estudio bíblico más detallado, de cada una de estas declaraciones, podemos responderlas de la siguiente manera:

a. Sobre el tema de la inmortalidad, cabe resaltar que todas las culturas de la antigüedad hacen un gran énfasis en la vida después de la muerte, lo cual obedece a un engaño de Sa-

${ }^{4}$ Jeremy Shepherd "Christian Enemy \#1: Dualism Exposed \& Destroyed", The Friday Symposium, Dallas Baptist University, 15 de octubre, 2004, http:// www3.dbu.edu/naugle/pdf/FridaySymposiumFa04/Christian_Enemy_1.pdf (consultado: 14 de diciembre, 2013). 
tanás: "No morirás" (Gen 3:4). Por otro lado, en el mismo relato del Génesis se puede ver que el hombre fue creado con una inmortalidad condicional, supeditada a la prohibición tocante al fruto del árbol de la ciencia del bien y del mal (Gen 2:1617), la cual fue una prueba de su obediencia y amor a Dios. Sin embargo, al desobedecer el ser humano, se le privó de dicha inmortalidad (Gen 3:22-24), llegando a ingresar la muerte dentro de la humanidad y de todo el mundo (Rom 5:12; 6:23). Y como consecuencia, el ser humano deja de existir, llegando a un estado de inconsciencia total, pues los muertos "nada saben y su memoria es puesta en olvido" (Ecl 9:5-6), y esto también involucra "el alma" (Ez 18:4). Por lo tanto, el ser humano fue creado con inmortalidad condicional, privilegio perdido por cau- sa de la desobediencia al mandato de Dios.

b. El ser humano fue creado a la imagen y semejanza de Dios. Entendiendo que los términos: imagen y semejanza, involucra el aspecto físico del ser humano (Gen 5:3), el aspecto mental, manifestado en el acto de señorear sobre todos los animales del campo (Gen 1:26; Sal 8: 6-8), de colocar nombre a cada una de las bestias (Gen 2:19), y el aspecto espiritual, manifestado en su capacidad de elegir libremente obedecer a Dios (Gen 2:16-17). Así, se puede inferir que el ser humano fue creado como una unidad física-mentalespiritual indivisible. Dentro de la cual, "el alma viviente" es la totalidad del hombre (Gen 2:7), a esto se añade que la Biblia llama a los animales como "almas vivientes” (Gen 1:20, 21, 24, 30; 2:19). Respecto a ello, la Biblia no hace 
alusión al alma como una entidad consciente, separada del cuerpo, sino por el contrario como la plenitud del ser humano (Gen 12:13; 42:21). Por lo tanto, la concepción del alma como la "parte buena" del ser humano, que se halla en contraste con el cuerpo (la parte mala), no tienen lugar dentro de la cosmovisión bíblica.

c. La Biblia muestra la universalidad de los principios divinos expresados en los 10 mandamientos, los cuales se enmarcan en cada momento de la vida, invitando al creyente a meditar en ellos "de día y de noche" (Jos 1:8; Sal 119: 97), y aunque el mejor momento para estar en comunión con Dios es en la mañana (Sal 5:3; Mar 1:35), Jesucristo mismo muestra en la metáfora de la vid, la gran necesidad de permanecer al lado de Cristo en todo momento,

sin separarse de él ni por un instante (Jn 15:4; 1 Tes 5:17). Esto involucra un adorar a Dios aun a través de las actividades comunes realizadas por el ser humano como: comer, beber, estudiar (1 Cor. 10:31), hablar (Mat 12:36; Col 4:6), trabajar (Stg 5:3-5) y hasta recrearnos y demás actividades, en las cuales espaciamos nuestra mente deben situarse en todo lo que es "verdadero, honesto, justo, amable y de buen nombre" (Fil 4:8).

d. Por lo tanto, cuando la Biblia habla de santidad del creyente, no se refiere solo al momento cuando estamos en el templo o en una actividad como la lectura de la Biblia o la oración. La Biblia presenta el llamado a ser perfecto como Dios lo es (Mat 5:48), a andar como Cristo anduvo (1 Jn 2:6), una santidad que involucra a la plenitud del ser del creyen- 
te, como lo enfatizó Pablo (1 Tes 5:23). Siendo claro que esto no involucra el enclaustramiento del creyente, ya que el maestro mismo replicó: "no ruego que los quites del mundo sino que los guardes del mal" (Jn 17:15).

De manera que la perspectiva idealista discrepa con la cosmovisión bíblica, que presenta no a un hombre dividido, sino a un hombre integral, quien lleva la mancha del pecado en todas las áreas de su vida pero, con la ayuda de Dios, puede iniciar el proceso de restauración de la imagen de Dios y vivir una vida que refleje el carácter de Dios.

\section{El Realismo}

Esta cosmovisión es contraria al idealismo, pues sostiene la existencia de un mundo real, percibido por los sentidos del espectador, existencia que es independiente de los esquemas conceptuales, lenguaje o creencias de las personas. En este sentido es contrario al idealismo, pues surge como una reacción hacia lo abstracto e irreal del pensamiento idealista. Por lo cual, el realismo busca la realidad de las cosas a través de todo aquello que es perceptible a los sentidos del ser humano, aseverando que la verdad consiste en la correspondencia de la mente con dicha realidad.

Esta cosmovisión sostiene que la creencia de la persona es solo una aproximación a la realidad, y que cada nueva observación que se realice de las cosas traerá un nuevo acercamiento de la persona hacia la realidad. Cabe recalcar que fue Aristóteles (384-322 a. C.), filósofo griego discípulo de Platón, quien coloca las bases filosóficas para el realismo, para quien la ciencia era el conocimiento de la causa de una cosa. Así, el realismo sería la ciencia de las primeras causas y principios. Aseverando, de este modo, la existencia de una esencia de las cosas, a la cual Aristóteles la denominó: forma, género, esencia o denominado en griego "ousía".

La diferencia entre estas pri- 
meras cosmovisiones es donde se ubica la esencia de las cosas, así mientras que el idealismo lo ubica en el campo trascendente (inalcanzable, lejano), el realismo la ubica en el campo inmanente (alcanzable, cercano). Para Aristóteles, las "ideas" solo llegan a ser entidades ficticias, pues lo que existen son los individuos. Aseverando que las ideas universales son solo abstracciones que el entendimiento realiza a partir de los individuos. Fue este enfoque el cual permitió llegar a la concepción de la forma o esencia universal, pero se la lo-

134 gra conocer a través del análisis y estudio de los objetos materiales y no de un mero razonamiento.

Más adelante, en la época moderna, Francis Bacon (1561-1629 d. C.) filósofo inglés, aportó la metodología inductiva, ${ }^{5}$ donde el hombre de ciencia debería analizar las cosas mediante observaciones validadas. Esto enfatiza que todo científico debe ser escéptico y aceptar solo las explicaciones que puedan ser probadas por la observación y la experiencia sensible. Fue este

${ }^{5}$ Entender lo desconocido a través de lo conocido. pensamiento el que dio las bases al actual método científico.

El impacto que esta cosmovisión ha tenido, en el desarrollo de las ciencias, es innegable, pues el realismo ha sido uno de los motores que ha generado el conocimiento científico. Siendo el realismo quien dio base para el desarrollo del modernismo, movimiento desarrollado principalmente en el siglo XVII, colocando a la razón y al método científico como las bases del conocimiento y, a la vez, mostrando un rechazo hacia toda autoridad tradicional, en manera especial hacia la autoridad religiosa.

Además, el modernismo fue implantando en la mente humana la noción del progreso, de la autonomía y de la realidad objetiva. Sin embargo, fracasa en su afán de perfeccionar a la sociedad por el solo uso de la razón, la estética y el desarrollo de la tecnología. El ideal de un mundo que goce de buena salud, longevo, feliz y bien alimentado tan enfatizado por el movimiento modernista no pudo salir adelante y, en su lugar, aparecieron dos guerras mundia- 
les. Dentro de la primera guerra mundial el costo humano fue de 8 millones de muertos, ${ }^{6}$ mientras que en la segunda guerra mundial dejó un total de 63 millones de muertos, ${ }^{7}$ esto sin contar la cantidad de personas heridas y desaparecidas que dejó cada guerra. Por lo cual, el modernismo históricamente falló en su afán de alcanzar metas humanísticas.

Por otra parte, al analizar en detalle esta cosmovisión, es necesario resaltar que para esta, la realidad última no está en la mera reflexión del por qué de las cosas (filosofar), sino en las mismas cosas, en los individuos. Por tal motivo, es el mundo físico lo que constituye la realidad. Es el análisis de estas cosas "materiales", por las cuales el hombre podrá llegar a conocer las leyes universales, que gobiernan todas las cosas.

${ }^{6}$ Spartacus Educational, Casualties: First World War, http://www.spartacus. schoolnet.co.uk/FWWdeaths.htm (consultado: 16 de enero, 2013).

${ }^{7}$ Second World War History, World War 2 Casualty Statistics http://www.secondworldwarhistory.com/world-war2-statistics.asp (consultado: 17 de enero, 2013).
Respecto a la epistemología del realismo, se puede mencionar que los conocimientos parten de los sentidos, es decir de la experiencia. Luego, una vez que han sido percibidos, será la inteligencia quien realizará la abstracción, pero, basado en cada uno de los datos sensibles. Es pues la verdad, un hecho que puede ser observado, de modo que la persona intenta descubrir cómo funciona el universo, pero observándolo.

Asimismo, en el campo de la axiología, el realismo considera que la naturaleza posee una ley moral hallada en la naturaleza, la cual el hombre debe descubrir y obedecer. Es la naturaleza quien tiene todos los criterios para la belleza. Por lo cual, un arte bello será aquel que refleje el orden y la lógica del universo, pero presentándolo como es y no como lo que se espera.

$$
\begin{aligned}
& \text { El realismo frente a la } \\
& \text { cosmovisión bíblica }
\end{aligned}
$$

Aunque la fuerza de esta cosmovisión ha ido menguando, todavía se puede percibir el énfasis con 
que algunas personas discriminan a la religión, acusándola de ser un tropiezo en el avance de la ciencia y de la emancipación de la persona, tomando como argumento el dogmatismo propio del oscurantismo de la Edad Media. Asimismo, el método científico elimina de sus axiomas la existencia de Dios y de los hechos sobrenaturales. Por lo cual, considera al cristiano que coloca a la Biblia, como la base de su vida, como una persona de mente estrecha, incapaz de hacer uso de la razón y de poder alcanzar a percibir la realidad y el verdadero conocimiento. Empero este pensamiento ya había sido anticipado por la revelación de Dios y advertido a todo creyente fiel, cómo debía ser su actuar frente a dicha cosmovisión.

Pablo, en su carta a los romanos, presenta el final de quienes tienen una cosmovisión que niega la existencia de Dios y que toma como medida del conocimiento al razonamiento de todo lo perceptible (léase Ro 1:20-25). Dentro de este pasaje, el apóstol inicia mostrando que todo aquel que verdaderamente busca a Dios, a través de la naturaleza, lo puede encon- trar: "Porque las cosas invisibles de él, su eterno poder y deidad, se hacen claramente visibles desde la creación del mundo" (Ro 1:20), enfatizando que no existe excusa para el estudiante.

Por otro lado, Pablo presenta una vislumbre de lo que acontece con todo aquel que se envanece en su razonamiento y niega a Dios, siendo el resultado "llegar a ser necio" (Ro 1:22) y su fin último: la vergüenza y la inmoralidad. Sin duda, la Palabra de Dios no se equivocó, pues junto al avance tecnológico del modernismo y el desarrollo de la "ciencia" en la búsqueda del desarrollo pleno del ser humano, solo aparecieron guerras, violencia, destrucción, falta de moral, junto a la aparición de enfermedades incurables y extrañas, como el caso del SIDA.

Pero cabe recalcar que la $\mathrm{Bi}$ blia no prohíbe el estudio de la naturaleza, ni el desarrollo de la ciencia. Muy por el contrario, la Biblia anima al cristiano a ser cabeza y no cola (Dt 28:13), a ser próspero en todas las áreas de la vida (Dt 28:10-12) y a ser una luz 
en medio de las naciones (Is 60:35). Para ello, la Biblia coloca como la base de la sabiduría: el "temor de Jehová” (Pro. 1:7), reflejado en un buscar primero el reino de Dios y su justicia (Mat 6:33), sabiendo que todo lo demás vendrá por añadidura. Esto claramente va en contra de las presuposiciones sobre las cuales está fundamentado el "realismo", ellas declaran "no hay Dios" (Sal 14:1-4). En conclusión, es claro notar que la diferencia mayor entre el realista y el cristiano está en la presuposición relacionada a la "existencia de Dios”. Es esta presuposición, hallada dentro de la mente del investigador, la cual traerá dos conclusiones totalmente contrarias, ante el análisis de un mismo objeto. Por ejemplo, al observar a un chimpancé, el realista verá en él a un antepasado de la raza humana que se halla en proceso de evolución, mientras el creyente verá uno de los animales creados por Dios.

Otro elemento, resaltante dentro de esta cosmovisión, es el rechazo hacia la Biblia como la $\mathrm{Pa}$ labra de Dios y su consideración como un libro de "tradiciones antiguas", tan igual como otros libros religiosos como "el Corán”, "los Vedas”, los cánones de Buda”, etc. Por lo cual, sostienen que no se puede considerar a estos libros como regla de vida, o revelación de Dios, sino solo como un libro de supersticiones y narraciones míticas y de relatos fabulosos similar a "la Ilíada" de Homero. Sin embargo, la Biblia ya, desde tiempos atrás, profetizó el desarrollo de esta cosmovisión en 2 Pe 3:3-6. Ante la cual aconsejó a su pueblo mantenerse firme frente a estas acusaciones. En primer lugar, la Biblia presenta un claro exclusivismo del mensaje divino, presentando a Cristo como el único camino de salvación (Hch 4:12), en contraste con Buda, los hindús y otras religiones, de manera que no existe comparación entre la Biblia y esos escritos; en segundo lugar, la Biblia presenta al Espíritu Santo trabajando en la mente y la conciencia de las personas a través de la naturaleza para presentarles el único camino de salvación (Jn 16:13; Ro 1:1415). Asimismo, la Biblia enfatiza la importancia del estudio de las 
Escrituras, pues solo ellas son capaces de hacer sabio a quien las lee (2 Tim 3:14-17), enfatizando la fe en Dios, como la base de la vida del creyente (He 11:6), una fe que solo puede desarrollarse en el creyente a través del oír y hacer lo hallado en las Sagradas Escrituras (Ro 10:17; 16:26, Stg 1:22-25). De manera que, un hombre que conscientemente niega a Dios, es incapaz de comprender las cosas que son de Dios (1 Co 2:14), de manera que para él, las cosas de Dios son locura (1 Co 1:23-24).

Sin embargo, esto no elimina el hecho que todos los creyentes deben estar "preparados para presentar defensa con mansedumbre y reverencia ante todo el que demande razón de la esperanza" que hay en cada creyente (1Pe 3:15). Asimismo, la Biblia considera el desarrollo del carácter del creyente y el cambio que Dios va realizando en su vida como una evidencia fundamental de la existencia de Dios (Mat 5:14-16) y como uno de los mejores argumentos para conducir a otra persona hacia el conocimiento de Dios. Seguido a ello, es necesario que el creyen- te pueda comenzar a presentar a Dios a través del libro de la naturaleza (Sal 19:1-4), mostrando en cada diseño y maravilla de la creación, la mano poderosa de Dios (Job 38:5-41; Sal 8:4-9), para luego poder presentar la Biblia como "la palabra de Dios” (2 Pe 1:19-21). Dependerá del empleo de estas tres herramientas, guiadas bajo el poder del Espíritu Santo, para poder persuadir a un realista hacia el conocimiento de Dios.

\section{El posmodernismo}

Esta corriente aparece a finales del siglo XX, popularizándose en el año 1979, con la publicación de la obra: La condición posmoderna de Jean-François Lyotard. Dicho pensamiento involucra a un amplio número de movimientos artísticos, culturales, literarios y filosóficos del siglo $\mathrm{XX}$, todos los cuales muestran en diversos grados y maneras su oposición o superación del modernismo. Entre sus principales ponentes se tiene a Richard Rorty (1931- 2007), filósofo estadounidense quien propuso que el lenguaje y el pensamiento 
no pueden dar una imagen clara de la realidad. Sus críticas se centraron en cuestionar a la cosmovisión basada en la metafísica, que parece obsesionada con ponerse en un lugar privilegiado para someter y limitar toda la realidad, bajo el juicio soberano de una razón omnipotente. Por otro lado, Jacques Derrida (1930-2004), ciudadano francés nacido en Argelia, quien es considerado uno de los más influyentes filósofos contemporáneos, propone la desconstrucción, que es un tipo de pensamiento que critica, analiza y revisa fuertemente las palabras y sus conceptos. Esto es necesario debido a que tanto autores como lectores han confundido los conceptos, introduciendo de esa manera dentro de los diferentes textos o discursos presuposiciones "inconscientes", que en realidad no fue lo que quiso decir el autor. Por lo tanto, se debe "desconstruir" los textos, quitando de él toda presuposición, juego de palabras, palabras escondidas, etc. Solo de ese modo se podrá volver a construir mejores teorías, que podría conducir al lector a perspectivas diferentes que, sin este proceso, no hubiese podido conocer.

Jean-François Lyotard (19241998), filósofo francés, criticó la sociedad actual postmoderna por el realismo del dinero, que se acomoda a todas las tendencias y necesidades, siempre y cuando tengan poder de compra. Como también criticó los metadiscursos: el cristiano, el iluminista, el marxista y el capitalista. Según Lyotard, estos son incapaces de conducir a la liberación.

Finalmente se tiene a Michael Foulcault (1926-1984), historiador de las ideas y filósofo francés quien exploró las implicaciones del poder que se hallan en el lenguaje. Además denunció que el conocimiento es socialmente construido por quienes tratan de legitimar su poder.

Este movimiento surge como una reacción ante el modernismo que, a través de la razón, logró el descubrimiento de diversas leyes en toda área de conocimiento, logrando de ese modo un desarrollo de la ciencia asombroso. Era pues la promesa del modernismo, que el descubrimiento de las verdades 
de la naturaleza capacitaría a las personas para controlar el mundo y con el tiempo se lograría un mundo mejor, pues con los conocimientos obtenidos se lograría vencer todas las limitaciones humanas, las enfermedades, el dolor y hasta quizá la muerte.

Sin embargo, la ciencia y la tecnología trajeron consigo la degradación del ambiente, la pugna por el poder y dos guerras mundiales. Sin lograrse divisar el mundo mejor que el modernismo había propuesto. Esto trajo como consecuencia reacciones, siendo

140 una de ellas el posmodernismo.

Aunque el posmodernismo no es una cosmovisión unificada, diferentes ponentes han planteado sus teorías, representa la convergencia de varios movimientos en diferentes disciplinas intelectuales, en manera principal por estas tres cosmovisiones bíblicas:

1. El pragmatismo: Debido a que la verdad se halla en constante cambio.

2. El existencialismo: El individuo es hacedor de su propia existencia, donde no hay valores absolutos.

3. El marxismo: El énfasis en las luchas de clases y los factores económicos.

Para una mejor percepción de la influencia del posmodernismo, se puede resumir las cuestiones ideológicas en los siguientes puntos:

1. La negación del conocimiento objetivo. Desde la perspectiva de esta cosmovisión, el conocimiento no es neutral debido a hallarse condicionado por las conclusiones individuales. De manera que cada persona define los objetos o llega a conclusiones de los acontecimientos externos basados en sus: (a)presuposiciones, (b)limitaciones, (c)nivel de educación y (d) lo aprendido en el pasado. Esto exalta el subjetivismo que existe en todo lo que el ser humano realiza. Por ejemplo, la cantidad de sal que se echa en la comida, 
la manera de peinarse, de vestirse. Donde cada persona tiene su gusto y el gusto de una persona es diferente al de otra.

Esta actitud, subjetiva de la realidad, minimiza el carácter universal de los principios eternos de las enseñanzas bíblicas.

Y, como consecuencia, cada persona tiene un gusto particular e interpreta las cosas de manera diferente, el posmodernismo rechaza la idea que existan principios universales a los que el ser humano tenga que sujetarse.

2. Todo sistema, para explicar los fenómenos, es incierto. Para esta cosmovisión, no existe ningún sistema seguro para explicar la verdad, y cuestiona aún el método científico. En contradicción al realismo, sostiene que la verdad no solo se puede alcanzar a través de la razón, sino también a través de otros medios como la intuición. Por lo cual, entendiendo que cada individuo tiene una perspectiva diferente, para esta cosmovisión todo es relativo, individualizado y circunstancial. Por consiguiente, toda aseveración social, moral o científica son solo teorías temporales y NADA puede aseverarse con certeza.

3. El conocimiento comunal define el conocimiento individual. Si bien es cierto que la verdad individual es correcta, dentro de un contexto social más amplio, el posmodernismo sostiene que la verdad es definida por la comunidad y lo realiza solo para ella misma, es decir, esta definición no es aplicable para otras comunidades. Esta perspectiva ha hecho posible que pequeños grupos que antes eran marginados, puedan gozar de 
una aceptación y respeto, de manera que hay comunidades religiosas $\mathrm{y}$ culturales que, dentro de su contexto, han creado dogmas adaptadas a sus costumbres y afiliaciones autóctonas.

4. La verdad es relativa y evoluciona constantemente. Este viene a ser uno de los aspectos más controvertidos que esta cosmovisión heredó del pragmatismo y existencialismo, como lo sostienen "la única verdad absoluta es que no existe verdad absoluta", de manera que alguien que comete un homicidio, solo ha cometido un desliz social, una falta de juicio. Esto arrastra del existencialismo, al sostener que es el individuo quien juzga lo que es bueno o malo, lo que es verdad o error. De modo que, al analizar la Biblia, el posmodernista la considera como una fuente de conocimiento más entre muchas otras, que busca el bienestar de los ciudadanos del mundo, pero jamás como la norma de conducta universal.
El posmodernismo frente a la cos- movisión bíblica

Frente a esta percepción propuesta por el posmodernismo, el aporte de la cosmovisión bíblica responde a través de tres premisas:

a. Sí existen verdades absolutas, las cuales no son ideas provisionales y sujetas al cambio.

$\mathrm{Al}$ abordar las Escrituras el tema de la verdad, se puede observar claramente dos fuentes de verdad: (1) la Biblia: la palabra escrita (Sal 119:43; Os 4:1), donde se describe a la verdad como las declaraciones dadas por Dios y comunicadas a los profetas (Am 3:7). Dichas declaraciones fueron escritas, reconocidas y aceptadas por la comunidad de los creyentes como "Pala- 
bra de Dios", formando lo que hoy denominamos como "Biblia" (Jn 17:17; Ef 1:13; Stg 1:18). Desde esta perspectiva, la verdad es la Palabra de Dios, es decir, la Biblia, y este libro debe ser la base a través del cual se debe medir todo conocimiento humano. (2) Cristo: La palabra viva (Heb 1:1-2; Jn 14:6), sin embargo, la Biblia presenta a Cristo como la persona "verdad". Siendo el medio a través del cual la divinidad se da a conocer a la humanidad.

Ambas fuentes de verdad son descritas como capaces de dar vida y gozan de permanencia eternal, como lo enfatiza Isaías (Is 40:8). Asimismo, se presenta una advertencia hacia aquel que añada algo a la Palabra de Dios (Prov 30:5-6), o que tal vez lo reemplace por las costumbres y tradiciones humanas (Mat 7:13), las cuales están más basadas en las cosmovisiones humanas y no según Cristo, la Palabra viva (Col 2:8).

Sobre esto, es necesario tener mucho cuidado, pues se debe comprender que existen cosas reveladas a los hombres, pero también existen otras que no las han sido. Y es en esto último, que muchos "cristianos" comienzan a argumentar y mencionar cosas que las Escrituras no revelan (Por ejemplo: la fecha de la venida de Jesús). Muchas veces, este atrevimiento cae en desmedro de la Palabra de Dios y muchos no creyentes piensan que la revelación de Dios es falible. Por lo tanto, sea el hablar de todo creyente: "¡A la ley y al testimonio!”, (Isa 8:20) o "escrito está" (Mat 4:4) y si no dijeren así, es porque aquel se halla en tinieblas o tan solo está manifestando una opinión, mas no la Verdad de la Palabra de Dios. 
b. La verdad debe ser buscada en el estudio de la autorrevelación de Dios.

Aunque la experiencia del ser humano, en contacto con la Biblia, es sumamente importante para el descubrimiento de la verdad, es la Biblia quien contiene las verdades reveladas de Dios. Y es por eso que la misma Biblia anima al estudiante a "escudriñar las Escrituras” (Jn 5:29; Hch 17:11), pues en ellas se podrá encontrar el testimonio de otro lado, es importante resaltar la labor del Espíritu Santo dentro de la búsqueda de la verdad (Jn 16:13). Pues es gracias a la labor, de la tercera persona de la deidad, que el ser humano es capacitado para alcanzar a comprender la verdad. Pues, de otro modo, sería imposible hacerlo (1Co 2:14).

En conclusión, el encuentro con la verdad, desde la cosmovisión bíblica, está

situado en la experiencia diaria del ser humano con el estudio de la Biblia, meditando en ella bajo la dirección del Espíritu Santo. A su vez todo otro conocimiento humano debe ser sometido a la luz de la verdad bíblica.

c. Los valores son absolutos y no varían de acuerdo a la cultura.

La Biblia muestra dentro de sus relatos históricos, la condición de la humanidad, donde la desobediencia, poligamia, asesinato, incesto, idolatría y una serie acontecimientos "malos" son descritos. Sin embargo, esto no es motivo para poder abrazar dicho comportamiento bajo la premisa equivocada de "todo lo que se halla descrito en la Biblia es bueno”. Pues, aunque la Biblia describe las acciones de hombres sujetos a debilidades, nos muestra a dónde condujeron cada 
uno de estos comportamientos, dándonos un ejemplo para no caer en el mismo pecado ( 1 Co 10:11). Por lo cual, toda acción descrita en la Biblia debe ser considerada a la luz de: (1) Los 10 mandamientos de Dios (Is 8:20) y (2) a dónde condujo ese comportamiento (Gal 6:7).

Por otro lado, la propia Biblia muestra que es posible contextualizar la verdad bíblica dentro de las diferentes culturas, y fue aplicado por Pablo (1 Co 9:20-23). Pero, a la vez, la Biblia enfatiza que esto no involucra los principios inmutables de Dios, es decir, los diez mandamientos. Donde el mismo escritor bíblico menciona en Gal 2:17,18, que Jesús no es ministro de pecado y que desde el momento en que una persona se convierte al Señor, destruye todo aquello que hacía antes. Pablo asevera que en cuan- to a la justicia que es en la ley, (él era) irreprensible (Fil 3:6), pero a la vez reconoce que se encontraba en una lucha, donde su mayor desafío era el "poner a su cuerpo bajo la dirección de Dios" (1 Co 9:27), entendiendo que solo así podría él podría ser un vencedor.

Los valores presentados en los mandamientos de Dios no son relativos, ni se aplican solo para un grupo de personas. Estos mandamientos son universales y ninguno tiene excusa de no saber de ellos, pues el juicio llega tanto a judíos como a gentiles (Ro 2:1116). Cabe resaltar que la imagen del juicio de Dios se ve desde el Génesis (en el diluvio) hasta el Apocalipsis (el lago de fuego y azufre) y aunque pocos cristianos, hoy en día, tocan este tema importante. La Biblia claramente enfatiza que "Dios traerá toda obra a juicio juntamente 
con toda cosa encubierta sea buena o mala" (Ecl 12:14).

Una peculiaridad del posmodernismo es tratar de aceptar creencias opuestas, sin cuestionar las diferencias. Para ello, esta cosmovisión enfatiza el vivir en armonía, a pesar de las diferencias filosóficas o ideológicas que pueden separar a las personas. Empero, la Biblia desafía a todo creyente a una vida de obediencia a Dios y a su Palabra, a vivir en la luz (Efe 5:8). Por otro lado, descri146 be a quienes rechazan el camino cristiano luego de haberlo conocido, como personas que viven en las tinieblas, de manera que el buen cristiano siempre estará alerta para no ser influido por estas cosmovisiones (2 Co 6:14-17; 1 Tes 5:5). Aunque claramente esto no involucra un enclaustramiento de parte del creyente, pues Dios nos llamó a ser luz en medio de las personas (Mat 5:14-16). Sin embargo, sí muestra un abstenerse de participar en acciones conjuntas que vayan en contra de los mandamientos de Dios (Jn 17:15), no importando que dichas personas sean nuestras autoridades (Ro 13:3-4; Hch 5:29).

\section{Conclusión}

Luego de haber analizado cada una de las cosmovisiones principales que aún pululan en la actualidad, podemos resumirlas de la siguiente manera:

\begin{tabular}{|l|l|l|l|}
\hline \multicolumn{1}{|c|}{ Cosmovisión } & \multicolumn{1}{|c|}{ Metafísica } & \multicolumn{1}{c|}{ Epistemología } & \multicolumn{1}{c|}{ Axiología } \\
\hline Idealismo & $\begin{array}{l}\text { Las ideas y la } \\
\text { mente }\end{array}$ & $\begin{array}{l}\text { Está en el mundo de las } \\
\text { ideas }\end{array}$ & Ley moral universal \\
\hline Realismo & $\begin{array}{l}\text { La naturaleza } \\
\text { (materia) }\end{array}$ & Es un hecho observable & La ley de la naturaleza \\
\hline Posmodernismo & $\begin{array}{l}\text { La individuali- } \\
\text { dad }\end{array}$ & No existe verdad objetiva & $\begin{array}{l}\text { El valor y lo bello lo de- } \\
\text { termina cada individuo }\end{array}$ \\
\hline
\end{tabular}


Ante cada una de estas cosmovisiones, la Biblia tiene una respuesta particular, que se ha ido desarrollando a lo largo del artículo. Asimismo, algunas citas de la mensajera del Señor (Elena G. White) son muy oportunas para lograr consolidar la perspectiva que el cristiano debería tener frente a estas cosmovisiones:

"La mente de la cual el error una vez se ha posesionado nunca puede extenderse libremente hacia la verdad, aun después de la investigación. Las antiguas teorías reclamarán reconocimiento. La comprensión de las cosas que son verdaderas, elevadas y santificadas será confusa. Las ideas supersticiosas penetrarán en la mente para mezclarse con la verdad, y serán siempre devastadoras en su influencia. El conocimiento cristiano lleva su propia estampa de superioridad sin medida en todo lo que concierne a la preparación para la vida inmortal y futura. Este distingue al lector y creyente en la Biblia-quien ha estado recibiendo los preciosos tesoros de la verdad-, del escéptico y el creyen- te en las filosofías paganas" ${ }^{\text {. "Por }}$ su poder engañador, Satanás había guiado a los hombres mediante vanas filosofías a poner en duda y, finalmente, a dejar de creer en la revelación divina y en la existencia de Dios. Podía contemplar panorámicamente un mundo de degradación moral y una raza expuesta a la ira de un Dios retribuidor del pecado. Con perverso triunfo, podía ver que había tenido tanto éxito en oscurecer la senda de tantos y que los había inducido a transgredir la ley de Dios. Revestía el pecado con atracciones agradables para asegurar la ruina de muchos"9. Dios nos pueda ayudar a consolidar la confianza en la Biblia, la palabra de Dios y, de esta manera, el lector creyente pueda evaluar las diferentes cosmovisiones, a través del contraste con la Biblia, la Palabra de Dios, y así poder dar respuesta con mansedumbre y reverencia acerca de la esperanza que hay en cada creyente que tiene a la Biblia, como la base de su cosmovisión. (1 Pe 3:15).

${ }^{8}$ Elena G. de White, El ministerio médico (Florida: Asociación Publicadora Interamericana, 2006), 116.

${ }^{9}$ White, Mensajes Selectos 1:317. 